\title{
Towards further defining the proteome of mouse saliva
}

\author{
Anne A Blanchard ${ }^{1,2}$, Peyman Ezzati ${ }^{3}$, Dmitry Shamshurin ${ }^{3}$, Andreea C Nistor ${ }^{1}$, Etienne Leygue 4 \\ John A Wilkins ${ }^{3}$ and Yvonne Myal ${ }^{1,2^{*}}$
}

\begin{abstract}
Background: Knowledge of the mouse salivary proteome is not well documented and as a result, very limited. Currently, several salivary proteins remain unidentified and for some others, their function yet to be determined. The goal of the present study is to utilize mass spectrometry analysis to widen our knowledge of mouse salivary proteins, and through extensive database searches, provide further insight into the array of proteins that can be found in saliva. A comprehensive mouse salivary proteome will also facilitate the development of mouse models to study specific biomarkers of many human diseases.

Results: Individual saliva samples were collected from male and female mice, and later pooled according to sex. Two pools of saliva from female mice ( 2 samples/pool) and 2 pools of saliva from male mice were used for analysis utilizing high performance liquid chromatograph mass spectrometry (nano-RPLC-MS/MS). The resulting datasets identified 345 proteins: 174 proteins were represented in saliva obtained from both sexes, as well as 82 others that were more female specific and 89 that were more male specific. Of these sex linked proteins, twelve were identified as exclusively sex-limited; 10 unique to males and 2 unique to females. Functional analysis of the 345 proteins identified 128 proteins with catalytic activity characteristics; indicative of proteins involved in digestion, and 35 proteins associated with stress response, host defense, and wound healing functions. Submission of the list of 345 proteins to the BioMart data mining tool in the Ensembl database further allowed us to identify a total of 283 orthologous human genes, of which, 131 proteins were recently reported to be present in the human salivary proteome.
\end{abstract}

Conclusions: The present study is the most comprehensive list to date of the proteins that constitute the mouse salivary proteome. The data presented can serve as a useful resource for identifying potentially useful biomarkers of human health and disease.

Keywords: Mouse/Human saliva, Biomarkers, Mouse salivary proteome, Mass spectrometry, Kallikreins

\section{Background}

The oral cavity is a unique environment colonized by bacteria and bathed in salivary fluid. Primarily considered as a component of the digestive process, saliva contains enzymes, including proteases, lipases and glycohydrolases which initiate partial digestion of food components [1]. Many of these enzymes are of bacterial origin and not derived from the salivary glands [1]. Salivary proteins also interact with the oral flora by binding microorganisms,

\footnotetext{
* Correspondence: yvonne.myal@umanitoba.ca

'Department of Pathology, Faculty of Health Sciences, University of

Manitoba, 770 Bannatyne Avenue, Winnipeg, Manitoba, Canada

${ }^{2}$ Department of Physiology and Pathophysiology, Faculty of Health Sciences,

University of Manitoba, Winnipeg, Canada

Full list of author information is available at the end of the article
}

resulting in their aggregation and facilitating their clearance from the oral cavity, serving as receptors for microbial adhesion to host surfaces, possessing antibacterial activity, or serving as microbial nutritional substrates [2]. Thus, saliva and the oral flora are intricately involved in the protection of the oral cavity.

Knowledge of the complexity of saliva in recent years has been expanded such that the term "salivaomics" was coined and is now used to encompass the salivary proteome, transcriptome, microRNA, metabolome and microbiome [3]. These "omes" form the platform for investigating salivary biomarkers for disorders ranging from cancer to infectious disease. The identification of salivary biomarkers of both oral and systemic disease has been a vigorously pursued area of research, primarily 
attributed to the fact that saliva collection is non-invasive, safe and inexpensive [1,4]. Salivary transcriptome and microbiota biomarkers were recently identified as diagnostic indicators of pancreatic cancer [5], and oral cancer [6] respectively. As well, soluble epidermal growth factor B2 (c-erbB2) has been identified in saliva of women with breast cancer [7]. Therefore salivaomics have shown much promise in cancer biomarker discovery [8].

Although saliva as a proximal biofluid of oral disease is intuitive, the detection of systemic disease is less clear. The mechanisms by which systemic disorders influence the salivome are not well understood. One proposed hypothesis is that blood-derived molecules enter salivary tissues via transcellular or paracellular routes and could potentially influence the molecular constituency of oral fluids $[9,10]$. More recently, the salivary proteome was shown to be altered through exosomes, microvesicular structures which deliver their contents from distal sites to other parts of the body including the salivary glands [3]. In cancer, it has been demonstrated that tumor-shed exosomes can shuttle proteins and other microbiological components to saliva, thereby altering both the proteome [11] as well as the transcriptome [12] of saliva.

To contribute to the goal of discovery of biomarkers from the salivary proteome, it is important to identify and catalogue the proteins in normal saliva. The human salivary proteome from healthy individuals was recently reported [13,14]. Knowledge of the salivary proteome of other species have not been well documented, with the exception of recent reports of the salivary proteome of goats and sheep [15], the bovine salivary proteome [16], and two recent studies of mouse saliva $[17,18]$. The most recent analysis of the mouse salivary proteome identified only 81 proteins [17], and therefore, a more in-depth analysis of the mouse salivary proteome is warranted.

The aim of the present study is to provide a more comprehensive listing by utilizing mass spectrometry analysis of the proteins that constitute the mouse salivary proteome, and to provide a reference list necessary for the utilization of mouse models in the study of salivary biomarkers. We report the most comprehensive list to date of proteins which constitute the mouse salivary proteome. Importantly, we also identify those proteins that were found common to both mouse and human. Our study contributes new knowledge to this growing field of proteomics that could also facilitate the diagnosis of human disease in a non-invasive way.

\section{Results and discussion}

\section{Identification of novel proteins in mouse saliva}

To identify the protein composition, saliva samples from both male and female mice were subjected to analysis by mass spectrometry as described in "Methods". Datasets from each of the 2 pools of saliva from female mice
( 2 pools, 2 mice per pool) were combined. Following the removal of duplicates, and implementation of a minimum criterion of two unique peptides and a score above -2 a list of 256 proteins was identified (Additional file 1). Analysis of saliva from the male mice resulted in a list of 263 proteins (Additional file 2). After merging the lists of proteins identified in males (263) with the proteins identified in females (256) and removing duplicates, 345 mouse salivary proteins were identified in this study (Additional file 3). Of the 345 proteins, 174 were found in both males and females, 89 were identified only in male saliva, while 82 were female specific (Figure 1). Importantly, these datasets represent the highest number of proteins identified to date from mouse saliva since a recently published list comprised of only 81 proteins [17].

\section{Delineating protein function through database analysis}

Functionally, the majority of proteins identified to date that are found in saliva fall into two categories: digestion and protection [1]. Therefore such findings would not be unexpected among the 345 we identified in this study. To investigate function, proteins were submitted to UniProt gene ontology database analysis [19]. One hundred

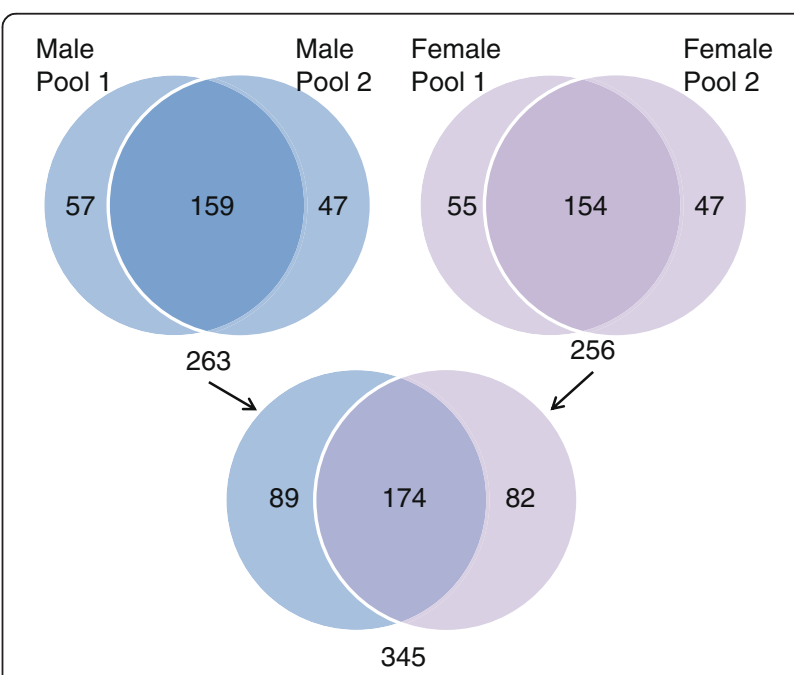

Figure 1 Venn diagrams of the protein datasets identified in mouse saliva. Two pools of female mice saliva (Female P1, Female P2) and 2 pools of male saliva (Male P1 and Male P2) were used in generating the Venn Diagram. Following the removal of duplicates, the datasets derived from the Female P1 and Female P2 were then combined, to generate a list of 256 proteins (Additional file 1). Further analysis revealed 154 proteins common to both pools of saliva. Similarly, datasets from the 2 male saliva pools were combined, resulting in a list of 263 proteins (Additional file 2). The compilation of data from Male P1 and Male P2 identified 159 proteins present in both samples. Datasets from the males and females were then combined to identify a total of 345 proteins: 174 proteins confirmed in datasets from both sexes as well as 82 proteins unique to the saliva from females and 89 unique to males (Additional file 3). 
and twenty-eight proteins were found to have catalytic activity, indicative of proteins involved in digestion. Of these, the largest group was the hydrolases, which include the kallikreins, cathepsins, amylases (Amy1, Amy2), adenosine deaminase (Ada), lactotransferin (Ltf), and chitinase (Chia). Twenty-nine additional proteins were identified as having enzyme regulatory activity components, the largest sub-group being the peptidase inhibitors which included the serpins and whey acidic protein (WAP) four disulfide core domain proteins (Wfdc2, Wfdc12, Wfdc18).

Expectedly, we also identified several proteins that play a role in protection of the teeth and soft tissues of the mouth, and non-immune host defense. It is well recognized that many salivary proteins interact with the microbiota of the oral cavity to promote the colonization of beneficial strains or the clearance of undesirable ones $[2,20]$. Of particular interest is the prolactin inducible protein, Pip, a protein first identified by us and shown to be highly abundant in both mouse and human saliva [21,22], and was found to be abundant in all 4 saliva sample pools ( 2 female pools, 2 male pools). We have previously shown that Pip can aggregate oral bacteria [23] inhibiting their activity. Further, using a Pip knockout mouse model we demonstrated that loss of Pip function had significant effects on both the diversity of the oral flora and abundance of specific bacteria of the oral cavity of the Pip null mouse [24]. One hundred and twenty-seven proteins that respond to stimuli were identified; 61 in response to stress stimuli, such as defense response ( 28 proteins), and wound healing (7 proteins). There was often overlap with regards to protein function and thus many fell into more than one category. Consequently, we combined the defense and wound healing linked proteins into one table which was comprised of 35 proteins (Table 1). Interestingly, the involvement of saliva in wound healing has long been recognized by oral surgeons and indigenous people as well [1].

Not surprisingly our list consists of several proteins whose functions are yet to be determined. One such protein is the $16.5 \mathrm{kDa}$ submaxillary gland glycoprotein (or salivary protein 1, Spt1) which was first identified by us [25]. Another is Dccp2, which shares homology with members of the common salivary protein-1/Demilune cell and parotid protein (CSP-1/Dccp) family of proteins, suggested to potentially have either antimicrobial or enamel protective activities [26]. Fifty-five other proteins were identified in the mouse saliva that do not have gene ontology annotations in UniProt (Table 2).

\section{Sex-linked proteins}

The small number of mice representing each sex (2 pools; total 4 mice) prohibited statistical analyses and limited conclusions regarding sex-related proteins. Nevertheless, several proteins showed sex-linked quantitative differences. In the present study we identified 82 proteins unique to females and 89 unique to males (Figure 1). However, when a protein was identified in one sex but underrepresented in the other sex by less than 2 peptides, they were not considered as being gender specific. Additionally, proteins that were not represented in both pools from each sex were eliminated. Consequently, a number of proteins were further removed from the gender specific sub-group. Table 3 lists 10 proteins exclusively detected in male saliva and only 2 proteins exclusive to females. Most of these proteins were not highly abundant as indicated by their intensity scores which were not in the top 100 proteins (Additional files 1 and 2). An exception was Klk1b24, a member of the kallikrein-related peptidase family of proteins. Klk1b24 was ranked in the top 40 proteins found in male saliva (Additional file 1), but was not detected in female saliva. The kallikreins and kallikreinrelated peptidases are a large family of serine proteases which play important roles in inflammation [27] and have recently been shown to be sex-linked [17]. However, we found that 11 of the 12 kallikrein-related peptidases that were reported as male-specific in the study by Karn et al. [17], were also present in female saliva (Additional file 3). Nonetheless, we detected that, based on the rank and number of unique peptides, 8 of these kallikrein-related peptidases displayed higher levels in males than females, whereas 3 did not show sex-linked quantitative differences in male and females. The levels of Klk1 and Klkb5 were similar in the saliva from both males and females (Additional file 4), in agreement with the observations of Karn et al. [17]. The identification of additional members of the kallikrein-related peptidase family of proteins in female saliva could simply be attributed to an increased depth of analysis, as substantially more proteins were identified in our study. Another plausible explanation could pertain to strain differences; the CD1 strain used in our study versus the C57BL/6 strain used in the Karn et al. study [17].

\section{Comparison of the mouse and human salivary proteome}

A catalogue of the human salivary proteome from healthy individuals was recently published by Denny et al. [13] identifying over 1100 proteins. This was preceded by a less extensive list published by Wilmarth et al., comprised of 102 proteins [14]. Defining orthologous relationships between two species presents a certain amount of difficulty as many proteins have evolved in different species to several forms and derivatives. For example, the five members of the cystatin family of proteins in the human saliva were represented in the mouse by two members, (gene symbols cst 3 and cst10); and lipocalin 1 and lipocalin 2 by four family members in the mouse (gene symbols lcn3, 4, 11, and 14). However, the BioMart 
Table 1 Mouse saliva proteins involved in host defense and wound healing

\begin{tabular}{|c|c|c|}
\hline $\begin{array}{l}\text { UniProt } \\
\text { accession }\end{array}$ & Gene symbol & Gene ontology (GO) \\
\hline Q14BX6 & 4933415F23Rik & innate immune response; regulation of phosphorylation \\
\hline P29699 & Ahsg & positive regulation of phagocytosis; regulation of inflammatory response \\
\hline Q61176 & Arg1 & response to interleukin-4, lipopolysaccharide, transforming growth factor beta \\
\hline P01887 & $\mathrm{B} 2 \mathrm{~m}$ & $\begin{array}{l}\text { defense response; phagocytic vesicle membrane; positive regulation of } \mathrm{T} \text { cell mediated } \\
\text { cytotoxicity; response to bacteria }\end{array}$ \\
\hline P97361 & Bpifa1 & antibacterial humoral response; innate immune response \\
\hline Q61114 & Bpifb1 & innate immune response \\
\hline P01027 & C3 & complement activation; inflammatory response; positive regulation of phagocytosis \\
\hline Q91XA9 & Chia & immune system process; positive regulation of chemokine secretion \\
\hline O35744 & Chil3 & inflammatory response \\
\hline P11087 & Col1a1 & response to transforming growth factor beta stimuli; tooth mineralization; wound healing \\
\hline O88207 & Col5a1 & cell adhesion; collagen biosynthetic process; extracellular fibril organization; wound healing \\
\hline Q9WVJ3 & Cpq & carboxypeptidase activity; metallodipeptidase activity; proteolysis; tissue regeneration \\
\hline P21460 & Cst3 & $\begin{array}{l}\text { cellular response to hydrogen peroxide, axon injury, hypoxia; response to nutrient levels; } \\
\text { response to toxic substance }\end{array}$ \\
\hline P13020 & Gsn & actin filament polymerization; aging; cilium morphogenesis; regulation of cell adhesion; tissue regeneration \\
\hline Q61646 & $\mathrm{Hp}$ & antioxidant activity; defense response to bacterium; immune system process; response to hypoxia \\
\hline O35664 & Ifnar2 & response to interferon-alpha; type I interferon receptor activity; type I interferon signaling pathway \\
\hline P01592 & lgj & adaptive immune response; antibacterial humoral response; innate immune response \\
\hline Q9Z1M2 & $\operatorname{lrgm} 2$ & defense response to bacterium; defense response to protozoan; response to interferon-gamma \\
\hline P00755 & Klk1b1 & bradykinin biosynthetic process; tissue kallikrein-kinin cascade; vasodilation \\
\hline P26262 & Klkb1 & blood coagulation; fibrinolysis; inflammatory response; plasminogen activation; \\
\hline Q61805 & Lbp & $\begin{array}{l}\text { defense response to Gram-negative/Gram positive bacterium; innate immune response; regulation of } \\
\text { chemokine production }\end{array}$ \\
\hline Q5SW46 & Lpo & defense response to bacterium; peroxidase activity; response to oxidative stress \\
\hline P08071 & Ltf & $\begin{array}{l}\text { antibacterial humoral response; antifungal humoral response; innate immune response in mucosa; } \\
\text { positive regulation of toll-like receptor } 4 \text { signaling pathway; regulation of cytokine production; regulation } \\
\text { of tumor necrosis factor production }\end{array}$ \\
\hline P17897 & Lyz1 & cytolysis; defense response to Gram-negative/ Gram-positive bacterium; lysozyme activity \\
\hline E9Q513 & Muc5b & defense response to bacterium; regulation of macrophage activation \\
\hline Q6LDU8 & $\mathrm{Ngf}$ & inflammatory response; response to lipopolysaccharide; response to radiation; sensory perception of pain \\
\hline 008692 & Ngp & defense response \\
\hline O88593 & Pglyrp1 & $\begin{array}{l}\text { defense response to Gram-positive bacterium; innate immune response; negative regulation of inflammatory } \\
\text { response; negative regulation of interferon-gamma production; negative regulation of natural killer cell differentiation }\end{array}$ \\
\hline P02816 & Pip & aspartic-type endopeptidase activity; regulation of immune system process \\
\hline 009049 & Reg3g & $\begin{array}{l}\text { MyD88-dependent toll-like receptor signaling pathway; defense response to Gram-positive bacterium; positive } \\
\text { regulation of wound healing }\end{array}$ \\
\hline P31725 & S100a9 & $\begin{array}{l}\text { chronic inflammatory response; innate immune response; leukocyte chemotaxis; neutrophil aggregation; } \\
\text { response to lipopolysaccharide }\end{array}$ \\
\hline P07758 & Serpina1a & acute-phase response; response to cytokine; response to peptide hormone \\
\hline Q80YQ1 & Thbs1 & $\begin{array}{l}\text { cellular response to growth factor stimulus; cellular response to tumor necrosis factor; chronic inflammatory } \\
\text { response; immune response; inflammatory response }\end{array}$ \\
\hline Q9JHY3 & Wfdc12 & defense response to bacterium; extracellular region; serine-type endopeptidase inhibitor activity \\
\hline P63101 & Ywhaz & histamine secretion by mast cell; response to drug \\
\hline
\end{tabular}

Submission of mouse salivary proteins to the UniProt gene ontology database identified 35 proteins with functions related to defense and/or wound healing. 
Table 2 Mouse salivary proteins with no known gene annotations

\begin{tabular}{|c|c|}
\hline UniProt & Description \\
\hline D3YTP1 & 2310057J18Rik (RIKEN cDNA 2310057 J18, isoform CRA_a) \\
\hline F7D4R8 & 5430401F13Rik (Fragment) \\
\hline E9PWS6 & A630073D07Rik \\
\hline E9QLA8 & A830010M20Rik \\
\hline F6QRE9 & BC007180 (Fragment) \\
\hline Q3UQ05 & Bpifb5 \\
\hline A2AJD1 & Bpifb9b \\
\hline E9PYC2 & Dcpp2 \\
\hline L7N259 & Dсpp3 \\
\hline E9Q0B5 & Fcgbp \\
\hline F6URP1 & Gm6619 (Fragment) \\
\hline A0A075B6A3 & Igha \\
\hline A0A075B5P2 & $\operatorname{lgkc}$ \\
\hline A2BHRO & Obp2b \\
\hline E9PYQ4 & Prol1 \\
\hline Q3TUY3 & Sbpl (Spermine binding protein-like) \\
\hline E9QA35 & Spata31d1a \\
\hline D3Z617 & Sval2 (Seminal vesicle antigen-like 2, isoform CRA_a) \\
\hline Q9DA65 & $16.5 \mathrm{kDa}$ submandibular gland glycoprotein \\
\hline Q8R1E9 & Allergen dl chain C2A (Androgen binding protein beta) (Androgen-binding protein) (Protein Scgb2b27) \\
\hline Q91WB5 & Androgen binding protein alpha (Androgen-binding protein) (Protein Scgb1b27) \\
\hline Q8JZX1 & Androgen binding protein gamma (Protein Scgb2b26) (Salivary androgen-binding protein gamma subunit) \\
\hline O35176 & Androgen-binding protein (Androgen-binding protein eta) (Lacrimal androgen-binding protein eta) (Protein Scgb1b2) \\
\hline D2XZ31 & Androgen-binding protein (Protein Scgb1b29) (Protein Scgb1b7) (Fragment) \\
\hline Q80XE3 & BC051076 protein (Protein BC051076) (Fragment) \\
\hline P07743 & BPI fold-containing family A member 2 (Parotid secretory protein) (PSP) \\
\hline Q8C1E1 & BPI fold-containing family B member 2 (Bactericidal/permeability-increasing protein-like 1) \\
\hline $\mathrm{A} 2 \mathrm{BGHO}$ & BPI fold-containing family B member 4 (Long palate, lung and nasal epithelium carcinoma-associated protein 4) \\
\hline Q8BU51 & BPI fold-containing family B member 6 (Bactericidal/permeability-increasing protein-like 3) \\
\hline Q9D6P8 & Calmodulin-like protein 3 \\
\hline Q99MQ5 & Collagen alpha-1(XXV) chain (CLAC-P) [Cleaved into: Collagen-like Alzheimer amyloid plaque component (CLAC)] \\
\hline Q03401 & Cysteine-rich secretory protein 1 (CRISP-1) (Acidic epididymal glycoprotein 1) (Sperm-coating glycoprotein 1) (SCP 1) \\
\hline Q03402 & Cysteine-rich secretory protein 3 (CRISP-3) (Acidic epididymal glycoprotein 2) (Sperm-coating glycoprotein 2) (SCP 2) \\
\hline P51655 & Glypican-4 (K-glypican) [Cleaved into: Secreted glypican-4] \\
\hline D3YWW2 & Golgi integral membrane protein 4 \\
\hline Q8BM72 & Heat shock 70 kDa protein 13 (Microsomal stress-70 protein ATPase core) \\
\hline B1AQ77 & Keratin 15, isoform CRA_a (Keratin, type I cytoskeletal 15) \\
\hline Q3UV17 & Keratin, type II cytoskeletal 2 oral (Keratin-76) (K76) (Type-II keratin Kb9) \\
\hline Q66VB7 & Lacrein (Protein Gm1553) \\
\hline Q14AJ3 & Lipocalin 3 (Vomeronasal secretory protein 1) \\
\hline J3QM75 & MCG1039283 (Protein Scgb2b19) \\
\hline D3YYY1 & MCG116526 (Protein Scgb2b7) \\
\hline G5E8B4 & MCG147827 (Secretoglobin family 2B member 2) \\
\hline G5E8B5 & MCG22579 (Secretoglobin family 1C member 1) \\
\hline
\end{tabular}


Table 2 Mouse salivary proteins with no known gene annotations (Continued)

\begin{tabular}{|c|c|}
\hline Q6GQX2 & Nck-associated protein 5-like \\
\hline Q02819 & Nucleobindin-1 (CALNUC) \\
\hline Q8BHEO & Proline-rich protein 11 \\
\hline Q91X93 & Proline-rich protein BstNI subfamily 1 (Protein Prb1) \\
\hline Q6PDI5 & Proteasome-associated protein ECM29 homolog (Ecm29) \\
\hline Q9CV82 & Protein 2310003L06Rik (Fragment) \\
\hline P97347 & Repetin \\
\hline Q920H1 & Secretoglobin family 3A member 2 (Pneumo secretory protein 1) (PnSP-1) (Uteroglobin-related protein 1) \\
\hline Q6JHY2 & Submandibular gland protein C \\
\hline Q61900 & Submaxillary gland androgen-regulated protein 3A (Salivary protein MSG1) (Submaxillary gland androgen-regulated protein 1) \\
\hline Q6ZPJ0 & Testis-expressed sequence 2 protein \\
\hline Q9CPT4 & UPF0556 protein C19orf10 homolog (Interleukin-25) (IL-25) (Stromal cell-derived growth factor SF20) \\
\hline Q5SXG7 & Vitelline membrane outer layer protein 1 homolog \\
\hline
\end{tabular}

Fifty-seven of the 345 proteins identified in mouse saliva, were found to have no gene ontology attributes in the UniProt database.

data mining tool in the Ensembl genome database (release 76, August 2014 [28]), provides a method of conversion with generally accepted results [29]. We submitted the list of 345 mouse salivary proteins to the BioMart data mining tool which identified 283 orthologous human genes and their corresponding Ensembl gene identification numbers (Additional file 5). Following this analysis, we then compared the mouse proteins with the human proteins identified by Denny et al. [13]. Since the 1166 human salivary proteins, reported by Denny et al. [13] were initially identified by International Protein Index (IPI), a database which has since been deactivated, the DAVID gene identification tool $[30,31]$ was then used to convert the $1166 \mathrm{hu}$ man protein list to 930 Ensembl gene identification numbers. Of the 283 orthologous genes identified by BioMart from our mouse salivary proteins, 131 were represented in the human salivary proteome (Additional file 5); 93 more than previously reported by Karn et al. [32]. A possible reason for protein differences between the present study and that of the human salivary proteome may be the method of collection (duct versus whole saliva). As well, dietary, hygiene, social and sexual behavior differences may also explain differences in the salivary proteome of the two species. For example, mice use saliva for their fur care, and also lick the fur of other group members for social purposes, or leave traces of saliva, presumably containing pheromone-like substances, to mark their territory. Humans have few remaining functions of saliva in a sociosexual context [33].

\section{Conclusions}

Saliva, as a non-invasive, efficient alternative for the diagnosis of systemic disease holds much promise. Indepth analysis of saliva is important to identify potential biomarkers of disease. Furthermore, such identification in the mouse can facilitate the development of mouse models to study specific biomarkers of many human diseases. The present study has provided the most in-depth analysis of the mouse salivary proteome to date, identifying 345 proteins. Mouse models are commonly used in the study of human diseases and it is well recognized that gender is an important variable that should be considered in many of these models [34-37]. In this study, a search for sex-linked proteins revealed several that were found in male saliva which were absent in females. Additionally, comparison of the mouse proteins with the recently published most extensive catalogue to date, of the human salivary proteome from healthy individuals [13], has allowed the identification of 131 proteins present in both human and mouse saliva. These studies therefore contribute further insight into the growing number of proteins that may be potentially useful biomarkers of health and disease.

\section{Methods}

\section{Saliva collection}

Mice were housed in the animal care facility at the University of Manitoba. All animal protocols were approved by the University of Manitoba Animal Care and Use Committee in accordance with the Canadian Council for Animal Care Guidelines. Saliva was collected at 7-8 weeks of age from 4 female and 4 male CD1 mice. Briefly, animals were anesthetized in a chamber infused with $4 \%$ isofluorane, and salivation was induced by subcutaneous administration of $10 \mathrm{mg} / \mathrm{kg}$ pilocarpine (Sigma-Aldrich Canada Co.Oakville, ON, Canada) in phosphate buffered saline. Saliva was collected with a pipet over a $15 \mathrm{~min}$ period and transferred to a microcentrifuge tube containing protease inhibitor (Complete Mini, Roche Diagnostics, Laval, PQ, Canada). The saliva was then vortexed for $1 \mathrm{~min}$, centrifuged at $16000 \mathrm{~g}$ for 5 min at $4^{\circ} \mathrm{C}$, transferred to a new tube, leaving behind 
Table 3 Sex-linked proteins.

\begin{tabular}{|c|c|c|c|}
\hline UniProt & Protein name & $\begin{array}{l}\text { Gene } \\
\text { symbol }\end{array}$ & Gene ontology (GO) \\
\hline \multicolumn{4}{|c|}{ A) Salivary proteins unique to male mice } \\
\hline Q9D6P8 & Calmodulin-like protein 3 & Calml3 & calcium ion binding \\
\hline Q8BHN3 & Neutral alpha-glucosidase $A B$ & Ganab & $\begin{array}{l}\text { Golgi apparatus; N-glycan processing; carbohydrate binding; endoplasmic reticulum; } \\
\text { glucan 1,3-alpha-glucosidase activity; glucosidase II complex; glucosidase activity; } \\
\text { melanosome; protein binding }\end{array}$ \\
\hline Q91XA2 & Golgi membrane protein 1 & Golm1 & $\begin{array}{l}\text { Golgi apparatus; integral component of membrane; nucleus organization; regulation } \\
\text { of lipid metabolic process }\end{array}$ \\
\hline Q61754 & Kallikrein 1-related peptidase b24 & Klk1b24 & proteolysis; serine-type endopeptidase activity \\
\hline Q63836 & Selenium-binding protein 2 & Selenbp2 & cytosol; membrane; nucleus; protein transport; selenium binding \\
\hline P70277 & $\begin{array}{l}\text { Alpha-N-acetylgalactosaminide } \\
\text { alpha-2,6-sialyltransferase } 2\end{array}$ & St6galnac2 & integral component of Golgi membrane; protein glycosylation; sialyltransferase activity \\
\hline B1AQJ2 & $\begin{array}{l}\text { Ubiquitin carboxyl-terminal } \\
\text { hydrolase } 36\end{array}$ & Usp36 & cysteine-type peptidase activity; nucleolus; ubiquitin-dependent protein catabolic process \\
\hline Q80YQ1 & Thrombospondin 1 & Thbs1 & $\begin{array}{l}\text { activation of MAPK activity; blood vessel morphogenesis; calcium ion binding; cell } \\
\text { adhesion; cell cycle arrest; cell migration; cellular response to growth factor stimulus; } \\
\text { cellular response to tumor necrosis factor; (abbreviated) }\end{array}$ \\
\hline J3QM75 & MCG1039283 (Protein Scgb2b19) & Scgb2b19 & extracellular space \\
\hline A2ANT6 & Major urinary protein 6 & Mup6 & extracellular region; pheromone binding; small molecule binding; transporter activity \\
\hline \multicolumn{4}{|c|}{ B) Salivary proteins unique to female mice } \\
\hline P29699 & Alpha-2-HS-glycoprotein & Ahsg & $\begin{array}{l}\text { acute-phase response; cysteine-type endopeptidase inhibitor activity; extracellular } \\
\text { space; negative regulation of bone mineralization; ossification; positive regulation of } \\
\text { phagocytosis; regulation of inflammatory response }\end{array}$ \\
\hline Q5GAN1 & Angiogenin ribonuclease 5 & Ang5 & endoribonuclease activity, producing 3'-phosphomonoesters; nucleic acid binding \\
\hline
\end{tabular}

Ten proteins found in mouse saliva were limited to males and 2 proteins were limited to females. Gene ontologies were derived from UniProt.

any precipitated debris from the mouth, and then stored at $-80^{\circ} \mathrm{C}$. This protocol excludes intact microorganisms present in the collected saliva from subsequently being processed with the salivary proteins.

\section{Sample preparation}

The protein concentration of each saliva sample was determined using the Pierce BCA assay kit (Fisher Scientific). Saliva samples collected from two female mice were combined in equal protein amounts to form a pooled sample (Female P1), and similarly pooled from the two other female mice (Female P2). Likewise, saliva collected from 4 male mice was combined into 2 pools (Male P1 and Male P2). Proteomic analysis was then carried out at the Manitoba Centre for Proteomics and Systems Biology at the University of Manitoba.

\section{Protein digestion and peptide purification}

A modified version of the filter aided sample preparation protocol [38] was used. Proteins from each pellet pool were resuspended in $1 \mathrm{ml}$ of lysis buffer (1\% [wt/vol] sodium dodecyl sulfate, $100 \mathrm{mM}$ Tris- $\mathrm{HCl}, 0.1 \mathrm{M}$ dithiothreitol $[\mathrm{pH} 7.6])$ and heated at $95^{\circ} \mathrm{C}$ for $5 \mathrm{~min}$ and subsequently centrifuged at $16,000 \times g$ for $20 \mathrm{~min}$. The resulting supernatant was transferred to an Amicon Ultra-15 $10 \mathrm{~K}$ filter device (Millipore, Billerica, MA) and washed three times in $12 \mathrm{ml}$ of urea solution $(8 \mathrm{M}$ urea in $0.1 \mathrm{M}$ Tris- $\mathrm{HCl}[\mathrm{pH} 8.5])$. Each wash step included centrifugation at $4,000 \times g$ for at least $10 \mathrm{~min}$ until the final volume remaining in the filter tube was $<0.5 \mathrm{ml}$. $100 \mathrm{mM}$-iodoacetamide solution (in $8 \mathrm{M}$ urea solution) was added to the filter device, and left at room temperature in the dark for $20 \mathrm{~min}$. After centrifugation, the filter membrane was washed twice with an additional $12 \mathrm{ml}$ of urea solution. A 50- $\mu$ l aliquot was taken from the filter unit and analyzed by using a BCA protein assay kit (Pierce Chemical Co., Rockford, IL) to estimate the total protein content of the sample. The filter membrane was washed twice with $12 \mathrm{ml}$ of $50 \mathrm{mM}$ ammonium bicarbonate in water, and the remaining protein was trypsin digested for $18 \mathrm{~h}$ at room temperature (trypsin/ protein ratio, $1 \mu \mathrm{g}: 100 \mu \mathrm{g})$. On the following day, the filter unit was transferred to a new collection tube and spun at $4,000 \times g$ for $10 \mathrm{~min}$, and the filtrate was retained for downstream analysis. The membrane was washed with $1 \mathrm{ml}$ of $0.5 \mathrm{M} \mathrm{NaCl}$, and the resulting filtrate was combined with the corresponding previous filtrate and stored at $-80^{\circ} \mathrm{C}$ and dried in speed vac. Dried peptides were resuspended in $0.1 \%$ TFA and desalted by $100-\mathrm{mm} \mathrm{C}_{18}$ column (5- $\mu \mathrm{m}$ Luna C18) [39]; Phenomenex, Torrance, CA) and eluted using 80\% (vol/vol) acetonitrile. Purified aliquots were lyophilized and redissolved in buffer 
A ( $0.1 \%$ formic acid in water). Peptide concentrations in the combined filtrate were measured using a NanoDrop spectrophotometer (Thermo Fisher Scientific Inc, MA, USA) for subsequent mass spectrometry analysis.

\section{Proteomic analysis by nano-RPLC-MS/MS}

Saliva samples were analyzed by nano-RPLC-MS/MS using an A splitless Ultra 2D Plus [Eksigent, Dublin, CA] system coupled to a high speed Triple $\mathrm{TOF}^{\mathrm{mm}} 5600$ mass spectrometer [AB SCIEX, Concord, Canada] as described previously [38-42] 3ug peptides from each pool were injected via a PepMap100 trap column $[0.3 \times 5 \mathrm{~mm}, 5 \mu \mathrm{m}, 100 \AA$, Dionex, Sunnyvale, CA], and a $100 \mu \mathrm{m} \times 150 \mathrm{~mm}$ analytical column packed with $5 \mu \mathrm{m}$ Luna C18(2) was used prior to MS/MS analysis. Both eluents A (water) and B (99\% acetonitrile) contained $0.1 \%$ formic acid as an ion-pairing modifier. The tryptic digest was analyzed with 180 minutes gradient. Eluent B had a gradient from $0 \%$ to $35 \%$ over 165 minutes, $35 \%$ to $85 \%$ in 1 minute and was kept at $85 \%$ for 5 minutes at a flow rate of $500 \mathrm{~nL} / \mathrm{min}$. Key parameter settings for the TripleTOF 5600 mass spectrometer were as follows: ionspray voltage floating (ISVF) $3000 \mathrm{~V}$, curtain gas (CUR) 25 , interface heater temperature (IHT) 150 , ion source gas 1 (GS1) 25, declustering potential (DP) $80 \mathrm{~V}$. All data was acquired using information-dependent acquisition (IDA) mode with Analyst TF 1.5 software [AB SCIEX, USA]. For IDA parameters, $0.25 \mathrm{~s}$ MS survey scan in the mass range of 400-1250 were followed by $20 \mathrm{MS} / \mathrm{MS}$ scans of $100 \mathrm{~ms}$ in the mass range of 100-1600 (total cycle time: $2.3 \mathrm{~s}$ ). Switching criteria were set to ions greater than mass to charge ratio $(\mathrm{m} / \mathrm{z}) 400$ and smaller than $\mathrm{m} / \mathrm{z} 1250$ with a charge state of $2-5$ and an abundance threshold of more than 150 counts. Former target ions were excluded for 5 seconds. A sweeping collision energy setting of $37 \pm 15 \mathrm{eV}$ was applied to all precursor ions for collisioninduced dissociation.

\section{Software analysis of protein identification and function}

Spectra files were generated using Analyst ${ }^{\circ}$ TF 1.6.2 Software and converted into mascot generic file format (.mgf) using AB SCIEX MS Data converter [AB SCIEX, Foster City, CA]. These files containing the MS/MS spectra information were submitted for protein identification by the X!Tandem GPM (http://www.thegpm.org). The following parameters were used: (i) enzyme, trypsin; (ii) one missed cleavage allowed; (iii) fixed modification, carbamidomethylation of cysteines (iv) variable modification, oxidation of methionine; (v) peptide tolerance, $20 \mathrm{ppm}$; and (vi) MS/MS tolerance, $20 \mathrm{ppm}$. LC-MS/MS data of were searched against the Mus musculus proteome. Any proteins identified as belonging to any species other than mouse were eliminated from our list.

\section{Additional files}

Additional file 1: Proteins identified in saliva from female mice. 256 proteins were identified by 2 or more unique peptides.

Additional file 2: Proteins identified in saliva from male mice. 263 proteins were identified by 2 or more unique peptides.

Additional file 3: Proteins identified in mouse saliva. 345 proteins were identified by 2 or more unique peptides.

Additional file 4: Comparative levels of kallikreins in saliva from male and female mice.

Additional file 5: Comparison between human and mouse salivary proteomes. 283 human genes orthologous to the mouse salivary proteins and their corresponding Ensembl gene identification numbers are shown. This list was aligned with the human salivary proteome [13], and 131 proteins were found common to both mouse and human saliva.

\section{Abbreviations}

2D-LCMS: Two dimensional liquid chromatography \mass spectrometry; DTT: Dithiothreitol; IAA: lodoacetamide; KO: Knockout; MS/MS: Tandem mass spectrometry; Pip: Prolactin inducible protein; TBS-T: Tris-buffered saline with 0.05\% Tween 20; TFA: Trifluoroacetic acid; WT: Wild-type.

\section{Competing interests}

The authors have no known competing interests either financial or personal between themselves and others that might bias the work.

\section{Authors' contributions}

YM and JAW, designed, supervised, and contributed intellectually to many aspects of the study. YM, JAW and AAB contributed to the writing of the manuscript. DS and PE carried out the mass spec analysis and the database identification of the proteins and ratios. AAB conducted the comparative database analyses and compiled the data. ET and AN contributed to revising the manuscript. All authors read and approved the final manuscript.

\section{Acknowledgements}

This study was supported by a grant from the Natural Sciences and Engineering Research Council of Canada and a grant from the Province of Manitoba, Department of Innovation, Energy and Mines.

\section{Author details}

${ }^{1}$ Department of Pathology, Faculty of Health Sciences, University of Manitoba, 770 Bannatyne Avenue, Winnipeg, Manitoba, Canada.

${ }^{2}$ Department of Physiology and Pathophysiology, Faculty of Health Sciences, University of Manitoba, Winnipeg, Canada. ${ }^{3}$ Department of Internal Medicine, Faculty of Health Sciences, University of Manitoba, Winnipeg, Canada. ${ }^{4}$ Department of Biochemistry and Medical Genetics, Faculty of Health Sciences, University of Manitoba, Winnipeg, Canada.

Received: 25 November 2014 Accepted: 13 February 2015

Published online: 25 February 2015

\section{References}

1. Ruhl S. The scientific exploration of saliva in the post-proteomic era: from database back to basic function. Expert Rev Proteomics. 2012;9(1):85-96.

2. Scannapieco FA. Saliva-bacterium interactions in oral microbial ecology. Crit Rev Oral Biol Med. 1994;5(3-4):203-48.

3. Wong DT. Salivaomics. J Am Dental Assoc. 2012;143(10 Suppl):19S-24.

4. Al Kawas S, Rahim ZH, Ferguson DB. Potential uses of human salivary protein and peptide analysis in the diagnosis of disease. Arch Oral Biol. 2012;57(1):1-9.

5. Zhang L, Farrell JJ, Zhou H, Elashoff D, Akin D, Park NH, et al. Salivary transcriptomic biomarkers for detection of resectable pancreatic cancer. Gastroenterology. 2010;138(3):949-57. e941-947.

6. Mager DL, Haffajee AD, Devlin PM, Norris CM, Posner MR, Goodson JM. The salivary microbiota as a diagnostic indicator of oral cancer: a descriptive, non-randomized study of cancer-free and oral squamous cell carcinoma subjects. J Transl Med. 2005;3:27. 
7. Streckfus C, Bigler L, Dellinger T, Dai X, Kingman A, Thigpen JT. The presence of soluble c-erbB-2 in saliva and serum among women with breast carcinoma: a preliminary study. Clin Cancer Res. 2000;6(6):2363-70.

8. Hu S, Arellano M, Boontheung P, Wang J, Zhou H, Jiang J, et al. Salivary proteomics for oral cancer biomarker discovery. Clin Cancer Res. 2008;14(19):6246-52.

9. Drobitch RK, Svensson CK. Therapeutic drug monitoring in saliva. An update. Clin Pharmacokinet. 1992;23(5):365-79.

10. Jusko WJ, Milsap RL. Pharmacokinetic principles of drug distribution in saliva. Ann N Y Acad Sci. 1993:694:36-47.

11. Lau CS, Wong DT. Breast cancer exosome-like microvesicles and salivary gland cells interplay alters salivary gland cell-derived exosome-like microvesicles in vitro. PLoS One. 2012;7(3):e33037.

12. Lau C, Kim Y, Chia D, Spielmann N, Eibl G, Elashoff D, et al. Role of pancreatic cancer-derived exosomes in salivary biomarker development. J Biol Chem. 2013;288(37):26888-97.

13. Denny P, Hagen FK, Hardt M, Liao L, Yan W, Arellanno M, et al. The proteomes of human parotid and submandibular/sublingual gland salivas collected as the ductal secretions. J Proteome Res. 2008;7(5):1994-2006.

14. Wilmarth PA, Riviere MA, Rustvold DL, Lauten JD, Madden TE, David LL. Two-dimensional liquid chromatography study of the human whole saliva proteome. J Proteome Res. 2004;3(5):1017-23.

15. Lamy E, da Costa G, Santos R, Capela ESF, Potes J, Pereira A, et al. Sheep and goat saliva proteome analysis: a useful tool for ingestive behavior research? Physiol Behav. 2009:98(4):393-401.

16. Ang CS, Binos S, Knight MI, Moate PJ, Cocks BG, McDonagh MB. Global survey of the bovine salivary proteome: integrating multidimensional prefractionation, targeted, and glycocapture strategies. J Proteome Res. 2011;10(11):5059-69.

17. Karn RC, Laukaitis CM. Positive selection shaped the convergent evolution of independently expanded kallikrein subfamilies expressed in mouse and rat saliva proteomes. PLoS One. 2011;6(6):e20979.

18. Lamy E, Graca G, da Costa G, Franco C, E Silva FC, Baptista ES, et al. Changes in mouse whole saliva soluble proteome induced by tannin-enriched diet. Proteome Sci. 2010;8:65.

19. The Universal Protein (UniProt) Resource. [http://www.uniprot.org/].

20. Ericson T, Pruitt $K$, Wedel $H$. The reaction of salivary substances with bacteria. J Oral Pathol. 1975;4(6):307-23.

21. Myal Y, Iwasiow B, Yarmill A, Harrison E, Paterson JA, Shiu RP. Tissue-specific androgen-inhibited gene expression of a submaxillary gland protein, a rodent homolog of the human prolactin-inducible protein/GCDFP-15 gene. Endocrinology. 1994;135(4):1605-10.

22. Myal Y, Robinson DB, Iwasiow B, Tsuyuki D, Wong P, Shiu RP. The prolactin-inducible protein (PIP/GCDFP-15) gene: cloning, structure and regulation. Mol Cell Endocrinol. 1991;80(1-3):165-75.

23. Nistor A, Bowden G, Blanchard A, Myal Y. Influence of mouse prolactin-inducible protein in saliva on the aggregation of oral bacteria. Oral Microbiol Immunol. 2009:24(6):510-3.

24. Nistor A. Investigations into the role of MPIP, the mouse homologue of hPIP/GCDFP-15, in innate host defense. Master's Thesis, University of Manitoba; 2008. http://hdl.handle.net/1993/3031.

25. Myal Y, Iwasiow B, Yarmill A, Shiu RP. A new member of the hormonally regulated rodent submaxillary gland glycoprotein gene family: CDNA cloning and tissue specific expression. Mol Cell Endocrinol. 1996;120(2):133-8.

26. Mullins JJ, Mullins LJ, Dunbar DR, Brammar WJ, Gross KW, Morley SD Identification of a human ortholog of the mouse Dcpp gene locus, encoding a novel member of the CSP-1/Dcpp salivary protein family. Physiol Genomics. 2006;28(1):129-40.

27. Sotiropoulou G, Pampalakis G. Kallikrein-related peptidases: bridges between immune functions and extracellular matrix degradation. Biol Chem. 2010;391(4):321-31.

28. Flicek P, Amode MR, Barrell D, Beal K, Billis K, Brent S, et al. Ensembl 2014. Nucleic Acids Res. 2014:42(Database issue):D749-55.

29. Guberman JM, Ai J, Arnaiz O, Baran J, Blake A, Baldock R, et al. BioMart Central Portal: an open database network for the biological community. Database (Oxford). 2011;2011:bar041.

30. da Huang W, Sherman BT, Lempicki RA. Systematic and integrative analysis of large gene lists using DAVID bioinformatics resources. Nat Protoc. 2009;4(1):44-57.
31. da Huang W, Sherman BT, Lempicki RA. Bioinformatics enrichment tools: paths toward the comprehensive functional analysis of large gene lists. Nucleic Acids Res. 2009;37(1):1-13.

32. Karn RC, Chung AG, Laukaitis CM. Shared and unique proteins in human, mouse and rat saliva proteomes: Footprints of functional adaptation. Proteomes. 2013:1(3):275-89.

33. Mandel ID. The functions of saliva. JDentRes. 1987; 66 Spec No:623-27.

34. Bierhaus A, Nawroth PP. Critical evaluation of mouse models used to study pain and loss of pain perception in diabetic neuropathy. Exp Clin Endocrinol Diabetes. 2012;120(4):188-90.

35. Chang HY, Mitzner W. Sex differences in mouse models of asthma. Can J Physiol Pharmacol. 2007:85(12):1226-35.

36. Kokras N, Dalla C. Sex differences in animal models of psychiatric disorders. Br J Pharmacol. 2014;171:4595-619.

37. Wilke M, Buijs-Offerman RM, Aarbiou J, Colledge WH, Sheppard DN, Touqui L, et al. Mouse models of cystic fibrosis: phenotypic analysis and research applications. J Cyst Fibros. 2011;10 Suppl 2:S152-71.

38. Wisniewski JR, Zougman A, Nagaraj N, Mann M. Universal sample preparation method for proteome analysis. Nat Methods. 2009;6(5):359-62.

39. Grigoryan M, Shamshurin D, Spicer V, Krokhin OV. Unifying expression scale for peptide hydrophobicity in proteomic reversed phase high-pressure liquid chromatography experiments. Anal Chem. 2013;85(22):10878-86.

40. Lao YW, Mackenzie K, Vincent W, Krokhin OV. Characterization and complete separation of major cyclolinopeptides in flaxseed oil by reversed-phase chromatography. J Sep Sci. 2014;37(14):1788-96.

41. Rydzak T, McQueen PD, Krokhin OV, Spicer V, Ezzati P, Dwivedi RC, et al. Proteomic analysis of Clostridium thermocellum core metabolism: relative protein expression profiles and growth phase-dependent changes in protein expression. BMC Microbiol. 2012;12:214.

42. Verbeke TJ, Spicer V, Krokhin OV, Zhang X, Schellenberg JJ, Fristensky B, et al. Thermoanaerobacter thermohydrosulfuricus WC1 shows protein complement stability during fermentation of key lignocellulose-derived substrates. Appl Environ Microbiol. 2014;80(5):1602-15.

\section{Submit your next manuscript to BioMed Central and take full advantage of:}

- Convenient online submission

- Thorough peer review

- No space constraints or color figure charges

- Immediate publication on acceptance

- Inclusion in PubMed, CAS, Scopus and Google Scholar

- Research which is freely available for redistribution 